\title{
EKSISTENSI BAHASA ARAB KONTEMPORER
}

\author{
M. Dzikrul Hakim Al Ghozali \\ Universitas KH. A. Wahab Hasbullah (UNWAHA) Tambakberas Jombang \\ adzik202@gmail.com
}

\begin{abstract}
In the present day, it can be seen that the existence Arabic is decreasing, because most people prefer to learn languages like English, Korean, Chinese, Japanese and others in part. It is regarded as an International Language that is already popular in the world. It is rare to learn Arabic. Nowadays Arabic is considered only an old language that has not been polished in the eyes of the general public and is seen as a religious language. In fact, Arabic is the language that pioneered the Science.
\end{abstract}

Keywords: Existence, Arabic Language, Contemporary.

\section{A. PENDAHULUAN}

Manusia adalah makhluk sosial yang tidak akan pernah lepas dari yang namanya bahasa sebagai sarana komunikasi. Manusia berkomunikasi menggunakan bahasa. Di dunia ini terdapat berbagai macam suku dan bahasa, diantaranya: Bahasa Arab, Bahasa Inggris, Bahasa Jepang, Bahasa China, Bahasa Indonesia dan lain sebagainya.

Bahasa Arab merupakan salah satu bahasa diantara beragam bahasa yang ada di dunia. Bahasa ini juga mengalami perkembangan sebagaimana bahasabahasa umat manusia lainnya. Terlebih, setelah Allah SWT memilih bahasa ini sebagai bahasa turunnya wahyu dan menjadi bahasa pengantar kitab suci umat Islam, al-Qur'an, menjadikan bahasa ini memiliki posisi penting sebagai salah 


\section{Dzikrul Hakim Al Ghozali}

satu bahasa dunia. Dengan dipilihnya Bahasa Arab sebagai bahasa al-Qur'an, secara tidak langsung memperluas penggunaannya dan mempertahankan eksistensinya selama kitab suci tersebut dibaca dan dijadikan rujukan bagi seluruh muslim. Karenanya, Bahasa Arab tidak hanya milik orang Arab atau negara-negara di kawasan Timur Tengah yang menjadikannya bahasa resmi, namun milik seluruh muslim di dunia. ${ }^{1}$

Bahasa Arab memiliki kebudayaan yang tinggi. Yaitu Kebudayaan Saudi Arabia terbentuk dan dipengaruhi dari dua sumber yang kaya akan inspirasi: yakni nilai-nilai keislaman yang terpersonifikasi melalui al-Qur'an dan AsSunnah serta prilaku para Salafus-Shalih, dan Bahasa Arab yang kata dan susunan kalimatnya terbentuk di wilayah Jazirah Arabia ini. Dari kedua referensi inilah, budaya, pemikiran dan sastra berkembang di Saudi Arabia, yang putraputranya merasa bangga karena mereka menjadi pewaris para pujangga besar yang dilahirkan di bumi ini. Mereka memahami betul akan tanggung jawab dan peran yang mesti mereka lakukan di alam modern saat ini. Sebagaimana tertera dalam Anggaran Dasar Pemerintahan, Negara berkewajiban memelihara kebudayaan, pemikiran dan sastra.

Sebagai bahasa yang memiliki sejarah panjang dan penutur yang luas, Bahasa Arab merupakan bahasa yang konsisten dari segi morfologis, sintaksis dan pengucapannya dan juga bahasa yang berkembang dari segi istilah, kosakata

1 .Abdul Karim Khalifah. al-Lughah al-'Arabiyyah 'ala madariji'l Qarni'l Wahid wa'l 'Isyrin. Amman: (Daar al-Gharb al-Islamy.. 2003). Abdul Karim Khalifah. al-Lughah al- 'Arabiyyah 'ala madariji'l Qarni'l Wahid wa'l 'Isyrin. Amman: (Daar al-Gharb al-Islamy. 2003). Hal. 12-13. 
dan makna. Sejak zaman dahulu, bahasa ini telah menjelma menjadi bahasa resmi negara (zaman Umayyah misalnya), bahasa resmi agama bahkan bahasa kehidupan. Seiring berkembangnya ilmu pengetahuan dan pemikiran, Bahasa Arab juga berperan aktif dalam perkembangan istilah-istilah ilmiah. Dahulu bila Bahasa Arab hanya meminjam, menerjemahkan dan menyerap (arabisasi) istilahisitlah ilmiah, beralih untuk menciptakan dan menemukan istilah-istilah ilmiah dan perkembangan pemikiran. Karya al-Kindi, Ibn Sina, al-Biruni, al-Farobi, Ibn Rusyd, Ibn Zahir dan ilmuwan muslim lainnya dalam berbagai disiplin ilmu merupakan contoh nyata andil besar Bahasa Arab dalam perkembangan ilmu pengetahuan. Alasan ini pula yang mendasari penulis buku “Rasa'il Ikhwani'sShafa" sekitar Abad IV H tidak menemukan instrumen yang tepat untuk menjelaskan istilah dalam filsafat, pemikiran ilmiah dan ilmu sosial selain dalam istilah Bahasa Arab, dengan kekayaan susunan kata dan aspek semantiknya yang luas, baik prosa maupun sya'ir. ${ }^{2}$

Walaupun sekarang di era masa kini bahasa Arab masih tetap eksis, karena banyak mengandung seni, seperti: ilmu Balaghah, Nahwu, Shorof, Mahfudzat dan lain-lain. Semua itu diadopsi oleh negara-negara di berbagai belahan dunia. Kenyataannya, di zaman sekarang banyak orang yang menganggap Bahasa Arab itu sangat asing di telinga, dan banyak orang yang mempelajarinya hanya karena tuntutan sekolah, belum ada kesadaran dari diri masing-masing. Bahkan, banyak

2. Ibid. Hal. 15. 


\section{Dzikrul Hakim Al Ghozali}

orang Islam yang tidak mengerti Bahasa Arab yang seharusnya orang Islam itu perlu untuk bisa berbahasa arab. Mereka mempunyai pedoman hidup yaitu AlQur'an, sedangkan al-Qur'an itu sendiri berbahasa Arab.

Untuk itu kajian teori dan realiti tentang eksistensi bahasa arab perlu di sajikan dalam artikel singkat ini, pada artikel ini penulis akan menguraikan tentang seberapa pentingkah peranan Bahasa Arab di dewasa ini, dan Bagaimana eksistensi Bahasa Arab kontemporer agar dapat kita ketahui deskripsinya secara gamblang.

\section{B. PEMBAHASAN}

\section{Pengertian Bahasa}

Istilah "bahasa" dalam bahasa kita (Indonesia) sama dengan "lughatun" dalam Bahasa Arab, “language" dalam Bahasa Inggris, "langue” dalam Bahasa Prancis, "taal" dalam Bahasa Belanda, "sprach" dalam Bahasa Jerman, "kokugo" dalam Bahasa Jepang, dan "bhasa" dalam Bahasa Sansekerta. ${ }^{3}$

Dari setiap istilah diatas, masing-masing mempunyai aspek khusus dengan masyarakat. Bahwa istilah itu adalah untuk menyebut suatu unsure kebudayaan yang mempunyai aspek sangat luas, sehingga merupakan faham yang tidak mudah dibatasi. Bahasa adalah alat verbal yang digunakan untuk

3. Akrom Malibary, dkk,Pedoman Pengajaran Bahasa Arab, (Jakarta: Proyek Pengembangan Sistim Pendidikan Departemen Agama R.I, 1976),hal. 19. 
berkomunikasi, sedangkan berbahasa adalah proses penyampaian informasi dalam berkomunikasi. Bahasa juga merupakan gambaran realitas. ${ }^{4}$

Dalam kehidupan, setiap bahasa mencerminkan aspek-aspek budaya masyarakat. Bahasa merupakan sistem verbal atau visual yang bersifat manasuka, yang digunakan oleh sekelompok orang dengan latar budaya tertentu sebagai sarana komunikasi dalam kehidupan mereka sehari-hari. ${ }^{5}$

Bahasa merupakan media komunikasi untuk menyampaikan idegagasan, dan setiap manusia menggunakan bahasa ketika dirinya ingin mengungkapkan perasaan dan pikirannya pada orang lain. ${ }^{6}$

Dari uraian diatas dapat disimpulkan bahwa bahasa merupakan alat utama untuk berkomunikasi dalam kehidupan manusia, tanpa bahasa manusia tidak akan bisa untuk berkomunikasi dan mengenal satu sama lain. Karena manusia merupakan makhluk sosial yang selalu ada ketergantungan kepada yang lain untuk bisa menjalani hidup dengan baik.

\section{Karakteristik Bahasa Arab}

Bahasa Arab memiliki 2 jenis, yaitu: bahasa Fushha'dan 'Amiyah.Yang di maksud dengan bahasa Fushaa' adalah ragam bahasa Arab baku yang digunakan dalam kesempatan-kesempatan resmi dan untuk kepentingan

${ }^{4}$. Kinayati Djojosuroto, Filsafat Bahasa, (Yogyakarta: Pustaka, 2006), hal. 34.

5. M. Zaka Al Farisi, Pedoman Penerjemahan Arab Indonesia Strategi, Metode, Prosedur, Teknik, Cet. 1, (Bandung: PT. RemajaRosdakarya, 2011), hal. 199.

6. Abdul Wachid dan Heru Kurniawan, Kemahiran Bebahasa Indonesia, Cet. 2, (Purwokerto: Kaldera Press, 2013), hal. 5. 


\section{Dzikrul Hakim Al Ghozali}

kondifikasi karya-karya puisi, prosa dan penulisan intelektual secara umum. Bahasa Arab Fushaa' adalah bahasa standar yang mengikuti kaidah-kaidah baku secara internasinal. Dengan kaidah inilah orisinalitasnya terjaga yang berlaku.

Bahasa 'Amiyah adalah ragam bahasa yang digunakan untuk urusanurusan biasa sehari-hari. Bahasa 'Amiyah ini berkembang pesat di masyarakat menengah ke bawah. Sehingga orang Indonesia mengartikannya sebagai bahasa pasaran. Para linguis modern memberikan sejumlah nama, yaitu: allughat al-'amiyah, al-syakl al-lughawi al-darij, al-lahjat as-sya'i'yah, al-lughat al-makiyyah, al-lahjat al-arabiyyah al-'amiyah al-lahjat al-darijah, al-lahjat al'amiyah, al-'arabiyyah al-'amiyyah,al-lughat al-darijah, al-kalam al-darij, alkalam al-'ami, dan lughat al-sya'b. ${ }^{7}$

Bahasa "Amiyyah disebut bahasa yang "menyalahi" aturan, karena bahasa ini dinilai tidak memiliki kaidah yang baku secara Internasional. Ciri yang membedakan bahasa Fushha' dan 'Amiyyah yaitu :

a. Bahasa Fushha' derajatnya sangat tinggi, jauh di atas dialek 'amiyyah yang berlaku dalam pergaulan sehari-hari. Karena bahasa ini hanya digunakan dan berlaku di kalangan orang-ornag yang berbakat dan berpendidikan. Al-qur'an dan Hadits Nabi juga hanya menggunakan bahasa fushha'.

7. Acep Hermawan, Metodologi pembelajaran bahasa Arab, cet. 2(Bandung: PT Remaja Rosdakarya, 2011), hal. 72 . 
b. Pada bahasa fushha' tidak memilki ciri sifat kedaerahan atau yang berkaitan dengan kabilah tertentu. Walaupun pada unsur dasar dan pokok bahasa fushha' berasal dari beberapa kabilah, tetapi sudah bercampur menjadi bentuk baru. Berbeda dengan bahasa "amiyyah yaitu bahasa ini selalu menampakkan ciri kedaerahan. Dengan demikian, bahasa 'amiyyah yang berkembang seperti di Mesir, ini tidak akan sama dengan yang berkembang di Irak, Sudan, Yaman, dan sebagainya. ${ }^{8}$

1) Munculnya Bahasa Arab Fushha'

Perkembangan dan sejarah formatif yang panjang telah dilalui oleh bahasa Arab. Masyarakat Arab pra-Islam terdiri atas beberapa kabilah dan mempunyai sejumlah dialek bahasa (al-lahjat al-'Arabiyyah al-qadimah) yang berbeda-beda akibat perbedaan kondisi khusus yang ada di masingmasing wilayah.

Dialek-dialek itu secara umum dikelompokan menjadi dua, yaitu:

a. Al-'Arabiyyat al-ba'idah (bahasa Arab yang telah punah). Yaitu yang mencakup dialek-dialek bahasa Arab bagian utara jazirah Arab dan sebagian dialek selatan. Al-'Arabiyyat al-ba'idah dikenal dengan sebutan al-'Arabiyyah al-nuqusy (bahasa Arab prasasti) karena ragam bahasa ini tidak pernah sampai kepada kita kecuali melalui prasastiprasasti yang belakangan ditemukan secara luas, dari Damaskus

\footnotetext{
${ }^{8}$ Ibid, hal. 199
} 


\section{Dzikrul Hakim Al Ghozali}

sampai wilayah al-Ula' di bagian utara Hijaz. Beberapa dialeg yang tergolong Al-'Arabiyyat al-ba'idah ini, seperti: dialekal-tsamudiyyah, alshafawiyyah, dan al-lihyaniyyah.

b. Al-'Arabiyyat al-baqiyah (bahasa Arab yang masih hidup). Yaitu dialek yang dipergunakan dalam qashidah (bahasa puisi) jaman jahiliah atau pra-islam, yang dipergunakan di dalam bahasa Al-qur'an, dan bahasa Arab dikenal sampai hari ini. Al-'Arabiyyat al-baqiyah adalah dialek yang selanjutnya disebut dengan al-'Arabiyah, bahasa Arab seperti yang dikenal dan dipergunakan dalam bebagai suasana formal hingga hari ini di bebagai belahan Negara Arab. Dialek ini merupakangabungan dari berbagai dialek yang berbeda, sebagian yang dominan berasal dari bagian utara jazirah Arab dan sebagian yang lain dari daerah selatan. Ragam bahasa inilah yang sekarang digunakan dalam berbagai tulisan berbahasa Arab, pidato-pidato, siaran-siaran dan jurnalistik. Sejak masa pra-Islam dialek ini sudah tersebar luas di jazirah dan menjadi lingua franca bagi masyarakat multikabilah. ${ }^{9}$

Sejak turunnya al-Qur'an kedudukan al-'Arabiyyah ini semakin kukuh. Dialek ini terus berkembang seiring meningkat intensitas interaksi masyarakat Arab dari berbagai kabilah melalui pasar-pasar

\footnotetext{
${ }^{9}$ Acep Hermawan, Metodologi pembelajaran bahasa Arab
} hal. 75 
mereka yang sekaligus dijadikan pasar festival seni dan satra. Pasarpasar zaman pra-Islam seluruhnya berjumlah delapan, dan yang sangat terkenal sebagai ajang unjuk kebolehan para sastrawan dalam bidang puisi dan pidato adalah 'ukazh, majannah, marbad, dzulmajaz, dan khaibar .

Sejak kedatangan Islam, kedudukan bahasa bersama (lingua franca) itu makin kokoh. Persepsi masyarakat mengenai ragam bahasa Arab pun mulai mengalami pergeseran. Sebelumnya mereka menganggap bahasa Arab al-Qur'an dan bahasa lokal setara, berikutnya penghargaan dan perhatian lebih ditunjukan kepada bahasa bersama yang notabene digunakan dalamal-Qur'an. Sebagai bahasa agama, di sampingkan keunggulan obyektif yang dimiliki, bahasa ArabalQur'an dianggap lebih pantas untuk digunakan.

Seiring berjalannya waktu, bahasa Arab al-Qur'an dijadikan bahasa baku bagi seluruh kabilah di Jazirah Arab. Bahasa baku inilah yang kemudian dipandang sebagai bahasa Arab Fushha'. ${ }^{10}$

2) Munculnya Bahasa Arab 'Amiyah

Upaya penggiringan bahasa hanya untuk menggunakan bahasa alQur'an yang notabene adalah bahasa Quraisy, memunculkan sejumlah masalah. Masyarakat yang berasal dari kabilah selain Quraisy tidak seluruhnya memilki kesiapan dan kemampuan menggunakan bahasa al-

\footnotetext{
${ }^{10}$ Ibid, hal. 120
} 


\section{Dzikrul Hakim Al Ghozali}

Qur'an secara baik dan benar. Akibatnya, terjadi sejumlah kesalahan dan fenomena penyimpangan bahasa ketika masyarakat mulai menggunakan bahasa fushha'. Prakik kesalahan dan penyimpangnan berbahasa itu disebut lahn.

Istilah lahn ini dikenakan awalnya pada kesalahan dan ketidaktaatan padai'rab, yaitu perubahan bunyi akhir kata karena perubahan kedudukannya dalam kalimat. Benih-benih lahn mulai muncul sejak jaman Nabi Muhammad SAW berupa perbedaan luknah (logat, cara bicara) di kalangan sahabat. Misalnya, Bilal yang berbicara dengan logat Habasyi', Shuhaib dengan logat Romawi, Salman dengan logat Persia, dan seterusnya.

Praktik lahn tidak hanya terjadi dalam bahasa lisan tetapi juga mulai merembet pada bahasa tulis, terutama sejak masa Umar bin Khattab. Fenomena lahn ini makin meluas sejak dilakukannya penulisan bukubukuberbahasa Romawi dan Qibtiyah (Mesir) ke dalam bahasa Arab, dalam surat menyurat, dan lain sebagainya.

Fenomena penyimpangan lahn adalah cikal bakal lahirnya bahasa amiyah, bahkan ia disebut sebagai bahasa 'amiyyahyang pertama. Berbeda dengan dialek-dialek bahasa Arab yang digunakan di sejumlah tempat local, bahasa 'amiyyahdianggap sebagai suatu bentuk perluasan bahasa yang tidak alami. 


\begin{abstract}
Dan bahasa arab 'amiyyah ini disebut bahasa yang "menyalahi" kaidah-kaidah orisinil bahasa fushha'. Karena bahasa dalam penyimpangan (lughat fi al-lahn) setelah bahasa (lahn fi al-Lughat). Akhirnya secara perlahan tapi pasti bahasa amiyah terus berkembang hingga menjelma sebagai bahasa yang berdiri sendiri. ${ }^{11}$
\end{abstract}

\title{
3. Histori Bahasa Arab
}

Bahasa diciptakan manusia berdasarkan jenis, warna kulit, tempat asal, dan keberadaan manusia itu sendiri. Bahasa juga memberikan manusia kekhasan agar dapat dikenali. Kemampuan manusia dalam mengekspresikan bahasa dengan jelas, teliti, dan teratur harus sesuai dengan pikiran karena bahasa saling terkait dengan pikiran manusia. Jika dilihat sejarah bahasa yang berkembang di peradaban negara-negara yang berbeda, maka didapati bahwa bahasa menjadi peran penting bagi sejarah karena bahasa digunakan untuk menghasilkan budaya, sastra, seni, dan ilmu. Beberapa ahli berpendapat: "Pada dasarnya, seprimitif apapun suatu bahasa dari suku paling barbar sekalipun, telah menunjukkan tingkat intelegensi yang tinggi dan peradaban yang maju. Kemajuan tingkat intelegensi ini dapat dilihat dari susunan kata yang digunakan saat berkomunikasi satu sama lain, dibandingkan masa-masa prasejarah dimana bahasa dan tulisan belum ditemukan". Pendapat tersebut tentu saja diutarakan oleh ahli yang telah mendalami "struktur bahasa" dan 


\section{Dzikrul Hakim Al Ghozali}

hubungannya dengan tingkat intelegensi manusia. ${ }^{12}$ Pendek kata, bahasa adalah cermin pola berpikir.

Di antara pendapat mengenai sejarah asal mula bahasa Arab dan perkembangan bahasa Arab yang paling global di antaranya adalah pendapat bahwa bahasa Arab merupakan bahasa tertua karena telah ada sejak jaman Adam, sehingga perintis tulisan Arab dan pola kalimat bahasa Arab adalah Adam. Pendapat ini merupakan pendapat yang paling klasik dan merupakan interpretansi secara langsung dari firman Allah, "Allah telah mengajari Adam pengetahuan tentang segala nama" (Q.S. al- Baqarah: 31). Dari dalil ini, mereka berpendapat bahwa nama-nama benda dan berbagai hal atau sifat di dunia ini telah diajarkan oleh Allah kepada Adam dalam Bahasa Arab. Bahkan pengikut pendapat ini lebih tegas menyatakan bahwa huruf Arab telah dikuasai oleh Adam tanpa belajar dan langsung dari Allah seketika, atau disebut sebagai sebuah mukjizat atau paling tidak sebagai karunia. ${ }^{13}$ Di bawah pengaruh Islam, bahasa ini menentukan bahasa Persia, Turki, Urdu, Melayu, Hausa dan Sawhili. Bahasa Arab menyumbang 40-60 persen kosakata dan pengaruh yang kuat pada tata bahasa, Ilmu Nahwu, dan kesustraannya. ${ }^{14}$

12. John Lyons. Al-Lughah wa Ilmu'l Lughah (Language and Lingustistics) Terj. Musthofa at-Tauny. (Kairo: Daaru'n Nahdhah al-‘Arabiyyah. 1987). Hal. 38-39 dan 42

${ }^{13}$.Prof. Dr. Sutrisno, M.Ag, Rekonstruki Pendidikan Bahasa Arab, (Yogyakarta: Pedagogia, 2010), hal. 35.

${ }^{14}$.Ismail R. Al-Faruqi dan Lois Lamnya Al-Faruqi, Atlas Budaya Islam,Penerjemah Ilyas Hasan, (Bandung: Mizan, 2003), hal. 59 


\section{Urgensi Mempelajari Bahasa Arab}

Di samping bahasa Arab mempunyai keunggulan, juga dalam mempelajari bahasa Arab mempunyai manfaat sangat banyak, diantaranya yaitu:

a. Dapat memahami ma'na kandungan al-Qur'an dengan mudah. Dan itu wajib bagi umat Islam.

b. Dengan belajar bahasa Arab akan bisa berkomunikasi dengan orang-orang Arab jika suatu saat kita berada di daerah Arabia.

c. Dengan belajar bahasa Arab akan bisa membaca kitab-kitab kuning dan sastra-sastra Arab yang mana adalah tonggak berdirinya kemajuan ilmu pengetahuan dari dulu hingga sekarang.

d. Bisa mengetahui bagaimana perkembangan sejarah perjalanan bahasa Arab.

e. Agar seni yang tinggi dari bahasa Arab tidak akan hilang.

\section{BahasaArab Kontemporer}

Seiring dengan perkembangan zaman, di era masa kini bahasa nasional maupun bahasa asing sudah memperlihatkan persaingan yang sangat ketat dalam pergaulan dan komunikasi. Dalam hal ini kebanyakan bahasa mempunyai hubungan interaksi dengan masyarakat selaras dengan perkembangan masyarakat sepanjang masa. Lahir dan berkembangnya bahasa 


\section{Dzikrul Hakim Al Ghozali}

dapat dipengaruhi oleh berbagai faktor, antara lain:Faktor sosial, kebudayaan/peradaban, Agama, dan Politik.

Di dunia ini terdapat berbagai macam suku, budaya, dan bahasa, diantaranya: Bahasa Arab, Inggris, Jepang, China, Korean, Mandarin, Indonesia dan lain sebagainya. Di zaman kontemporer, melihat eksistensi (keberadaan) bahasa Arab semakin menurun, karena sekarang ini bahasa Arab sudah dianggap hanya bahasa zaman dulu dan tidak begitu penting yang dipandang hanya sebagai bahasa Agama.

Maka perkembangan bahasa Arab hanya terbatas dalam lingkungan kaum muslimin. Hanya sebagian kecil yang menyadari bahwa bahasa Arab selain sebagai bahasa agama juga sebagai ilmu pengetahuan yang melahirkan karya-karya besar dalam berbagai bidang ilmu filsafat, sejarah, sastra dan lainlain.

Dalam sejarah perkembangan ilmu pengetahuan di dunia, bahasa Arab telah memberikan sumbangan yang besar dan memegang peranan penting. Dunia barat pada abad pertengahan masih diliputi suasana kegelapan, disaat itu ilmu pengetahuan dan filsafat Yunani telah disimpan dalam bahasa Arab dalam bentuk terjemahan. Sehingga hampir semua buku-buku ilmu pengetahuan yang kenamaan diwaktu itu telah di terjemahkan ke dalam bahasa Arab. Maka bahasa Arab dalam dunia keilmuan dikenal sebagai bahasa Ilmu pengetahuan. Pada masa kebangkitan (Renaissance) di Barat, 
bahasa Arab ini berperan penting sebagai penghubung antara Yunani kuno dengan Eropa modern dengan jalan menterjemahkan kembali buku-buku ilmu pengetahuan dari bahasa Arab ke dalam bahasa Barat. ${ }^{15}$

Bagi orang Islam, sangat penting untuk mempelajari bahasa Arab karena orang Islam memiliki pedoman hidup yaitual-Qur'an Al-Karim, dan merupakan mukjizat terbesar Nabi Muhammad SAW yang di dalamnya menggunakan bahasa Arab, jika tidak mengerti bahasa Arab maka tidak akan bisa memahami isi kandungan al-Qur'an tersebut. Dan bahasa Arab juga merupakan bahasa Syurga. Karena di syurga nanti tidak memakai bahasa yang lain selain bahasa Arab.

Kesadaran akan bahasa ini penting karena akan menunjang berbagai unsur-unsur budaya lainnya seperti telah dijelaskan di atas. Berbagai ahli Bahasa Arab, baik dari negara Arab maupun negara non-Arab, turut menunjukkan optimisme mereka akan kemampuan Bahasa Arab untuk berdiri sejajar, bahkan menyaingi, peran Bahasa Inggris sebagai bahasa internasional. Tokoh-tokoh seperti Prof. A. Ghuwaidi dari Italia, Prof. Richard Kochhel dari Columbia University, Lemans ahli budaya Timur dari Jesuit, Prof. William Labov dari Amerika, Khalil Mutran sastrawan Mesir-Suriah, Muhammad Kurd Ali dari Damaskus dan Prof. Jabr Dumit dari American University of Beirut dalam buku “Fataawa Kibaari'1 Kuttab wa'1 Udabaa fi Mustaqbali'1

${ }^{15}$ Ibid, hal. 62 


\section{Dzikrul Hakim Al Ghozali}

lughah al-'Arabiyyah" menyatakan bahwa Bahasa Arab merupakan bahasa yang lintas budaya dan lintas negara. Sebagian besar negara-negara di Asia Barat dan Afrika Utara ( \pm 26 negara) menjadikan Bahasa Arab sebagai bahasa resmi negara mereka dengan dialek masing-masing. ${ }^{16}$

Bahasa Arab memiliki beberapa keunggulan,’Usman Amin (1965) memaparkan karakteristik bahasa Arab secara filosofis, karakteristik ini dipandangnya sebagai keunggulan bahasa Arab atas bahasa-bahasa lain di dunia. Menurutnya karakteristik pokok bahasa Arab itu dapat dilihat dari segi: kaitan mentalistik subyek-predikat, kehadiran individu, retorika paralel, keberadaan i'rab, dinamika dan kekuatan. Nayif Ma'ruf menambahkan adanya keutamaan makna, kekayaan kosakata, integrasi dua kata, dan analogi.

Penjelasanya yaitu: kaitan subyek-predikat, keberadaan I'rab, kekayaan kosakata, integrasi dua kata, dinamika dan kekuatan. Diantara contohcontohnya yaitu:

a. Keberadaan I'rab

Salah satu keistimewaan bahasa Arab adalah keberadaan I'rab.I'rab, menurut lughawi berarti menerangkan dan menjelaskan. Sedangkan menurutistilah berarti berubahnya harakat akhir karena perubahan kedudukannya dalam kalimat. Keberadaan $i^{\prime} r a b$ dalam bahasa Arab sangat penting sekali, karena perubahan harakat akhir merupakan tanda adanya

16. Sa'id Bengrad. Fataawa Kibaari'l Kuttab wa'l Udabaa fi Mustaqbali'l lughah al'Arabiyyah. (Qatar: Wizaaratu’ts Tsaqaafah wa'l Funuun wa’t Turaats. 2013). Hal. 24 - 43. 
perubahan kedudukan, dan adanya perubahan kedudukan berarti adanya perubahan makna. I'rab inilah yang menjelaskan hubungan antarkata pada suatu kalimat dan susunan kalimat dalam kondisi yang variatif. I'rab adalah tanda baca yang diwujudkan dalam bentuk fathah (penanda bunyi a), kasrah (penanda bunyi i), dhamah (penanda bunyi u), dan sukun(penanda huruf mati).

Dengan tanda inilah setiap kata di dalam sebuah kalimat menjadi jelas. Kemudian pembaca akan mudah dalam membedakan subjek, predikat, dan objek.

Suatu hari Abu Al-Aswad Al-Dauli mendengar seseorang membaca Al-Qur'an seperti berikut ini:

$$
\text { إن الله بريء من المشركين ورسوله...(التوبة:ץ) }
$$

Yaitu dengan meng-kasrah-kan huruf lam pada ورسوله (wa rasulihi). Padahal seharusnya dengan men-dhamah-kannya (warasuluhu).

Lalu al-Dauli berkomentar: tidaklah mungkin Allah berlepas dari Rasul-Nya. Komentar ini berarti bahwa jika lam pada kata tersebut dibaca kasrah, maka akan berarti Allah terlepas dari orang-orang musyrik dan Rasul-Nya. Sedangkan jika dibaca dhamah, maka akan berarti Allah dan rasul-Nya terlepas dari orang-orang musyrik. Atas dasar ini, alQur'an pun di beri I'rab. 


\section{Dzikrul Hakim Al Ghozali}

Kasus ini menunjukan bahwa I'rab dalam bahasa Arab sangat menentukan makna. Akan terjadi penyimpangan makna yang sangat jauh jika salah dalam i'rab. Maka sangat penting untuk dipelajari terutama orang Islam. ${ }^{17}$

b. Kekayaan kosakata

Kosakata adalah satuan terkecil yang ikut menentukan kekuatan bahasa. Memang setiap bahasa memiliki kosa kata tetapi tentu saja tidak sama. Menurut penelitian para ahli bahasa Arab sangat dikenal kaya akan kosakata, terutama pada konsep-konsep yang berkenaan dengan kebudayaan dan kehidupan mereka sehari-hari.

Untuk melihat kekayaan kosakata dalam bahasa Arab bisa dilihat pada kata tentang konsep haus, misalnya, yang erat kaitannya dengan kondisi orang Arab. Kata ini memilki sejumlah kosakata yang menggambarkan derajat kehausan seseorang. Penjelasannya sebagai berikut:

Jika seseorang ingin minum, maka keinginannya itu cukup diungkapkan dengan العطش/al-'athasy.

Jika العطش الظماء menguat, maka diungkapkan dengan/al-zhama'.

Jika الصدى الظماء/ الصداء/al-shada'.

Jika الصدى lebihg kuat lagi, maka diungkapkan dengan الأوام/al-awam.

\footnotetext{
${ }^{17}$ Ismail R. Al-Faruqi dan Lois Lamnya Al-Faruqi, Atlas Budaya Islam,Penerjemah Ilyas Hasan ...........,
} hal. 138 
Jika الأوام/al-hiyam.

Kata yang terakhir ini menggambarkan rasa haus yang luar biasa sehingga identik dengan datangnya kematian.

Dalam bahasa. Indonesia, khususnya, derajat kualitas semacam ini biasanya diungkapkan dengan kata sarana yang menunjukan perbandingan, misalnya kata lebih, amat, sangat, dan lain-lain, bukan dengan satu kata seperti dalam bahasa Arab.

Dalam memperkaya peran kosakata bahasa Arab memiliki 4 media, yaitu:

1) Taraduf (sinonim).

Adalah beragam kata dalam satu makna.

2) Isytirak (homonim).

Adalah beragam makna yang mengacu pada satu kata. Atau satu kata yang menunjukan pada makna banyak. Dengan cara diungkapkan lewat kata-kata, sehingga melahirkan kosakata.

3) Tadhadh (antithesis-polisemi)

Adalah suatu kata yang menunjukan makna tertentu sekaligus kebalikannya. Pada dasarnya tadhadh adalah bagian dari isytirak, hanya saja makna di dalam tadhadh adalah dua berlawanan.

4) Isytiqaq

Adalah bisa diartrikan sebagai pengambilan suatu kata dari kata lain dengan menjaga kesesuaian makna atau juga merubah bentuk 


\section{Dzikrul Hakim Al Ghozali}

suatu kata kedalam bentuk lain dengan menjaga keserasian makna antara keduanya. ${ }^{18}$ membagi isytiqaq ke dalam 4 kategori, yaitu:

1. Isyiqaq shagir (kecil)

2. Isyiqaq kabir (besar)

3. Isyiqaq akbar (lebih besar) atau abdal

4. Naht

c. Integrasi dua kata

Interaksi dua kata adalah dua kata yang memiliki makna berbeda, lalu diungkapakan dalam bentuk kata yang menunujuikan dua (mutsanna) secara morfologi dan sudah menjadi istilah baku dalam bahasa Arab. Aspek integrasi dua kata merupakan keistimewaan dan hanya ada dalam bahasa Arab.

\section{KESIMPULAN}

Bahasa Arab memiliki 2 jenis, yaitu : bahasa Fushha'dan 'Amiyah. Keunggulan bahasa Arab yaitu: 1) Bahasa Arab selain sebagai bahasa Agama juga sebagai ilmu pengetahuan yang melahirkan karya-karya besar dalam berbagai bidang ilmu filsafat, sejarah, sastra dan lain-lain. 2) Bahasa Arab adalah bahasaal-Qur'an Al-Karim, mukjizat terbesar Nabi SAW. 3) Bahasa Arab merupakan bahasa Syurga karena di syurga nanti tidak memakai bahasa

\footnotetext{
18. Ibid, hal. 139
} 


\section{Eksistensi Bahasa Arab Kontemporer}

yang lain selain bahasa Arab. Bahasa Arab mempunyai karakteristik pokok, yaitu: 1) Kaitan subyek-predikat, 2) I'rab, 3) Kekayaan kosakata, 4) Integrasi dua kata, 5) Dinamika dan kekuatan.

Di dewasa ini eksistensi (keberadaan) bahasa Arab semakin menurun, karena sekarang ini bahasa Arab sudah dianggap hanya bahasa zaman dulu dan menganggap tidak penting untuk mempelajarinya karena bukan merupakan bahasa Internasional yang mendunia, dan hanya sebagai bahasa Agama. Maka perkembangan bahasa Arab hanya terbatas dalam lingkungan kaum muslimin dan sedikit yang berminat mempelajarinya.

\section{DAFTAR PUSTAKA}

Al Farisi, M. Zaka. 2011. Pedoman Penerjemahan Arab Indonesia Strategi, Metode, Prosedur, Teknik. Cet 1. Bandung: PT. Remaja Rosdakarya.

Bengrad, Sa'id. 2013. Fataawa Kibaari'l Kuttab wa'l Udabaa fi Mustaqbali'l lughah al'Arabiyyah. Qatar: Wizaaratu'ts Tsaqaafah wa'1 Funuun wa't Turaats.

Djojosuroto, Kinayati. 2006. Filsafat Bahasa Yogyakarta: Pustaka.

Hermawan, Acep. 2011.Metodologi pembelajaran bahasa Arab. Cet. 2. Bandung: PT Remaja Rosdakara.

Khalifah, Abdul Karim. 2003. al-Lughah al-'Arabiyyah 'ala madariji'l Qarni'l Wahid wa'l 'Isyrin. Amman: Daar al-Gharb al-Islamy.

Lyons, John. 1987. Al-Lughah wa Ilmu'l Lughah (Language and Lingustistics) Terj. Musthofa at-Tauny. Kairo: Daaru'n Nahdhah al-'Arabiyyah. 


\section{Dzikrul Hakim Al Ghozali}

Malibary, Akrom, dkk. 1976. Pedoman Pengajaran Bahasa Arab. Jakarta:Proyek Pengembangan Sistim Pendidikan Departemen Agama R.I.

Wachid, Abdul, Kurniawan, Heru. 2013. Kemahiran Bebahasa Indonesia. Cet. 2. Purwokerto: Kaldera Press. 